\title{
The Usage of the Terms Mandibular Canal, Inferior Alveolar Canal, and Inferior Dental Canal in the Academia: A Bibliometric Analysis
}

\author{
El Uso de los Términos Canal Mandibular, Canal Alveolar Inferior \\ y Canal Dental Inferior en la Academia: Un Análisis Bibliométrico
}

Andy Wai Kan Yeung

YEUNG, A. W. K. The usage of the terms mandibular canal, inferior alveolar canal, and inferior dental canal in the academia: A bibliometric analysis. Int. J. Morphol., 39(4):1058-1062, 2021.

SUMMARY: A recent study found that the mandibular canal might be preferably called the inferior alveolar canal in recent publication years, certain journal categories, countries and departments with which the authors were affiliated. The canal can also be called the inferior dental canal that was not included in that study. This bibliometric analysis was conducted to evaluate the entire relevant literature, and to investigate if inferior alveolar canal was trending over the years. The Web of Science Core Collection electronic database was searched to identify publications exclusively mentioning mandibular canal, inferior alveolar canal, inferior dental canal, and publications mentioning them in combinations. Publication year, country of contributing authors, journal category, journal title, and citation count were recorded for the resultant publications. There were 1152 publications analyzed. Mandibular canal has always been the dominating term since the 1990s, whereas inferior alveolar canal seemed to become slightly more popular in the 2010s than in the past. Journals from dentistry, surgery, radiology, anatomy, and medicine all showed a preference towards mandibular canal. Leading dental surgery journals had a higher ratio of inferior alveolar canal usage than their dental radiology counterparts. Top 20 countries showed a preference towards mandibular canal except Saudi Arabia, which had $57.7 \%$ of publications using inferior alveolar canal exclusively. Publications mentioning mandibular canal, inferior alveolar canal, and inferior dental canal did not differ in averaged citation count. The term mandibular canal was still dominating in all academic fields. The term inferior alveolar canal showed increased usage in the 2010s without an increasing trend. The argumentation of renaming mandibular canal as inferior alveolar canal has yet to accumulate considerable traction.

KEY WORDS: Dentistry; Anatomy; Mandibular canal; Inferior alveolar canal; Inferior dental canal.

\section{INTRODUCTION}

The synonymous terms mandibular canal (MC), inferior alveolar (nerve) canal (IAC), and inferior dental (nerve) canal (IDC) have been used interchangeably in the academic literature. It was argued that since the mandible contains multiple foramina, the canal opening, mandibular foramen, should be renamed as inferior alveolar foramen and thus the term IAC should be a more appropriate representation of the canal (Iwanaga et al., 2021). This argumentation, based on its nature, should be established in the distant past. However, it was unclear if this school of thought has accumulated popularity and support in the academic literature. This can be considered as a conceptual replication and a complementary study of (Iwanaga et al.), who analyzed the 50 most recently published papers using the term MC and IAC, respectively. They found that $\mathrm{MC}$ was not always the preferred terminology in terms of publication year, journal category, country of first author, and author affiliation. In the current study, the entire relevant literature was analyzed. The temporal profiles of the publication counts, prevalence of IDC, and the usage of terms within the leading dentistry subspecialty journals were investigated.

\section{MATERIAL AND METHOD}

Screening. The Web of Science (WoS) Core Collection electronic literature database was queried on 2 March 2021 with the following search strings: (\#1) TS = ("inferior alveolar nerve canal" OR "inferior alveolar canal”); (\#2) TS = "mandibular canal"; (\#3) TS = ("inferior dental ca- 
nal" OR "inferior dental nerve canal"). TS refers to the topic field in WoS that covers the title, abstract, and keywords of the publications. Boolean operators were added to produce different combinations of these search strings to obtain publications that specifically used one term but not the other two. An additional filter was placed to exclude papers published in 2021, since year 2021 was not over yet at the time of writing this report. The numbers of publications are illustrated as a Venn diagram in Figure 1.

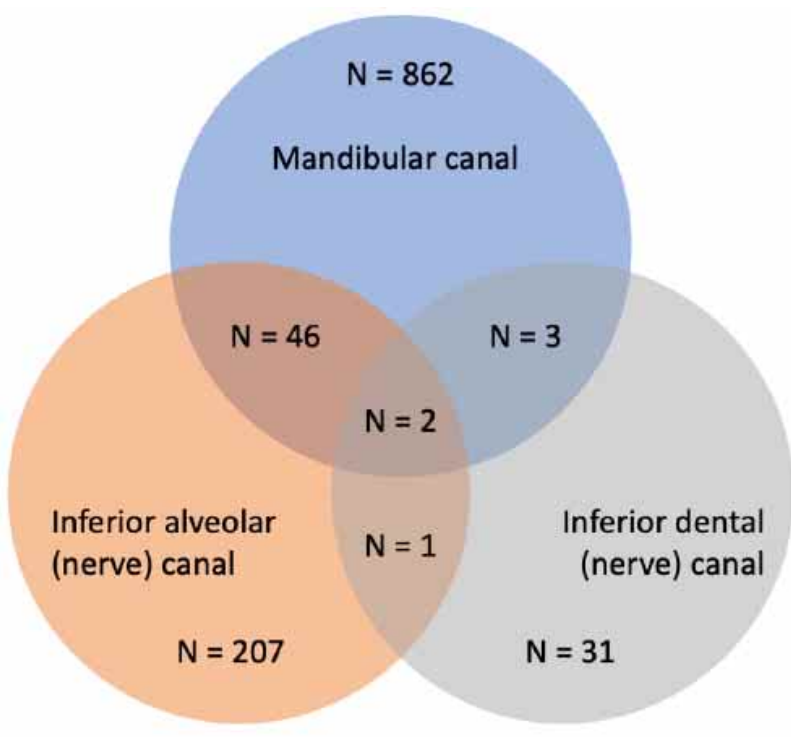

Fig. 1. Venn diagram showing the number of publications that used the different terms to describe the mandibular canal.

Data collection. The following parameters were recorded for the resultant publications: publication year, country of contributing authors, WoS journal category, journal title, and citation count.

Statistical analysis. The dominance of the term MC was tested in the top five recurring journal categories, the top two recurring dental radiology and dental surgery journals respectively, and the top 20 recurring countries. Binomial tests were conducted to evaluate if "exclusively MC" dominated over "exclusively IAC" and "exclusively IDC". Only publications falling into one of these three conditions were included into the tests. Null hypothesis was that the proportion of "exclusively MC" should be $33 \%$. Finally, Kruskal-Wallis test was performed to evaluate if publications that exclusively used the term MC,IAC, or IDC had significantly different citations between them. Statistical analyses were performed in SPSS 26.0(IBM, NY, USA). Results were considered significant if $\mathrm{P}<0.05$.

\section{RESULTS}

Publication year. There were a total of 1152 publications: 862 exclusively used the term MC, 207 exclusively used IAC, 31 exclusively used IDC, and 52 used them interchangeably. Among the 52, two mentioned all three terms because they were literature reviews and used all terms as literature search words (Mortazavi et al., 2019a,b).

MC has always been the dominating term since the 1990 s, whereas IAC seemed to become slightly more popular in the 2010s than in the past (Fig. 2). The annual publication count for exclusively using the term MC rose from around 30 in the early 2010 s to around 60 in the late 2010s, whereas the annual count for exclusively using IAC remained at around 10-20 across the entire 2010s. Before 1990, there were 29 publications that exclusively used the term MC, and the number for IAC and IDC were one and seven, respectively. These numbers seemed to suggest that MC remained the dominating term across the entire academia.

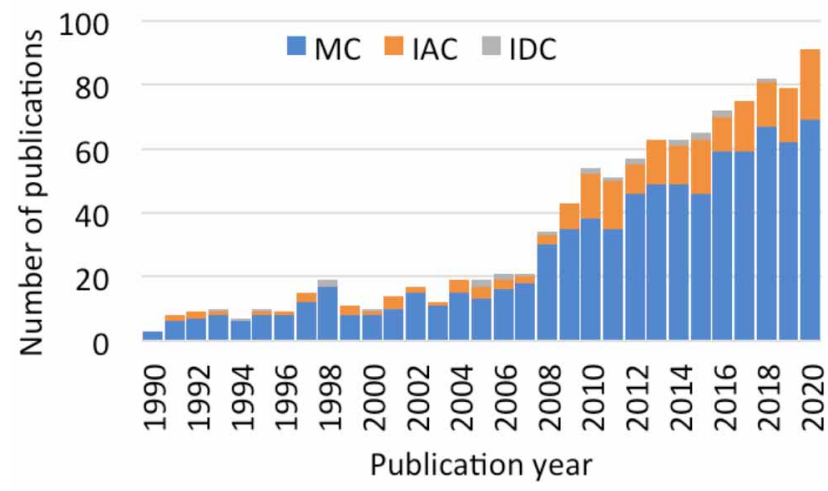

Fig. 2. The annual trend of publications exclusively used the term mandibular canal (MC), inferior alveolar canal (IAC), and inferior dental canal (IDC) respectively.

Journal category. The most recurring WoS journal categories were dentistry, oral surgery and medicine (hereafter "dentistry", $\mathrm{N}=756$ ), followed by surgery (171), radiology, nuclear medicine, and medical imaging (hereafter "radiology", 160), and anatomy and morphology (hereafter "anatomy", 99). The fifth category was medicine, general internal (hereafter "medicine") with a much lower count (50). Figure 3 shows that MC was the dominant term in these five journal categories. Even though the term IDC contains the word "dental", its usage was still a minority in dentistry journals. The counts of exclusively MC, IAC, and IDC in dentistry journals was 548,147 , and 26 respectively, equivalent to a ratio of $21: 6: 1$. The MC:IAC ratios in dentistry, surgery, 
radiology, anatomy, and medicine were $3.7: 1,3.0: 1,6.0: 1$, 10.8:1, and 2.0:1. The proportion of exclusive use of IAC, therefore, seemed to be highest in medicine and lowest in anatomy. Binomial tests showed that all five categories showed a preference towards MC $(\mathrm{P}<0.001)$.

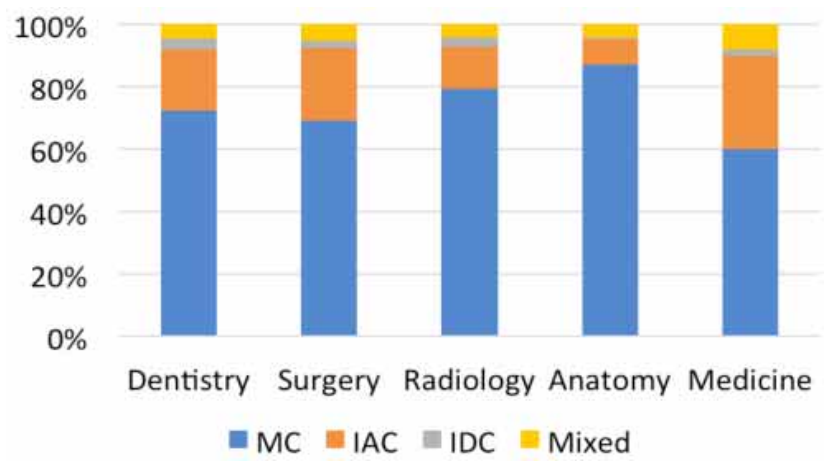

Fig. 3. The top five recurring journal categories and their usage of the terms mandibular canal (MC), inferior alveolar canal (IAC), and inferior dental canal (IDC).

Dental radiology and surgery journal. Since MC is most relevant to dental radiology and lower third molar surgery, data from the top two recurring dental radiology and dental surgery journals were explored (Fig. 4). They were Journal of Oral and Maxillofacial Surgery $(\mathrm{N}=85)$, Dentomaxillofacial Radiology (65), International Journal of Oral and Maxillofacial Surgery (42), and Oral Radiology (19). Again, binomial tests showed that all four journals showed a preference towards MC $(\mathrm{P}<0.001)$. While the two dental radiology journals showed a MC:IAC ratio of around 7.5-8.5:1, the two dental surgery journals showed a lower ratio of around 2.0-2.2:1.

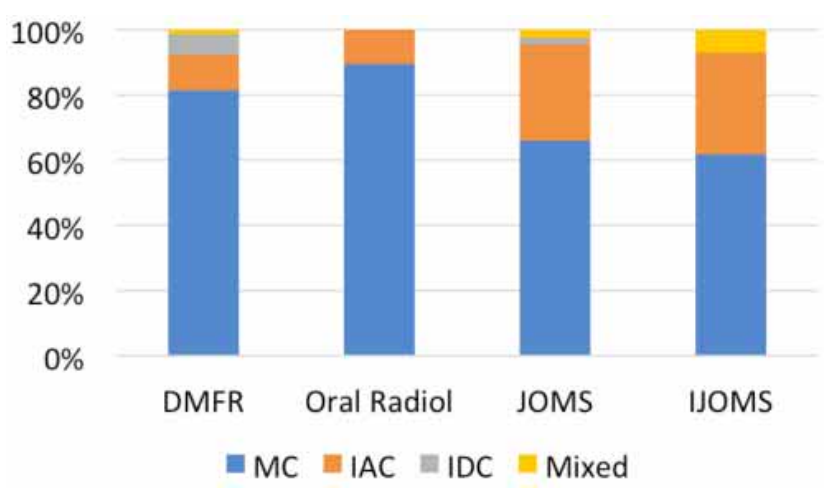

Fig. 4. The top two recurring dental radiology and dental surgery journals and their usage of the terms mandibular canal (MC), inferior alveolar canal (IAC), and inferior dental canal (IDC). DMFR, Dentomaxillofacial Radiology. Oral Radiol, Oral Radiology. JOMS, Journal of Oral and Maxillofacial Surgery. IJOMS, International Journal of Oral and Maxillofacial Surgery.
Country. The top 20 countries are listed in Figure 5. All of them had at least 21 publications in the analyzed literature set. Most of them seemed to favor the term MC $(\mathrm{P}<0.001$; for Iran, $\mathrm{P}=0.001)$ with the exception of Saudi Arabia $(P=0.304)$. The latter favored the term IAC, with $57.7 \%$ of its publications exclusively used the term IAC.

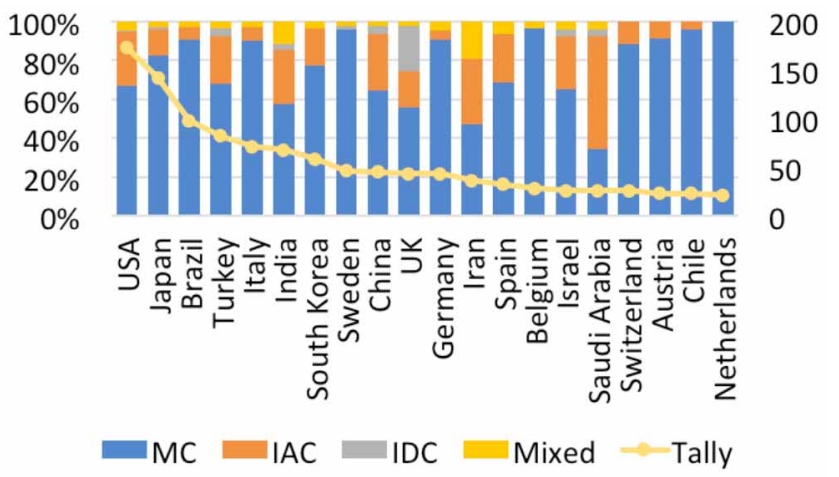

Fig. 5. The top 20 countries and their usage of the terms mandibular canal (MC), inferior alveolar canal (IAC), and inferior dental canal (IDC). The total publication counts of the countries are shown in the line chart (Y-axis on the right).

Citation. Publications exclusively used MC had a median of 6.0 citations, whereas the median was also 6.0 for IAC, and 9.0 for IDC. Kruskal-Wallis test showed no significant differences between the three groups $(\mathrm{P}=$ $0.786)$.

\section{DISCUSSION}

This analysis on a literature set composed of 1152 publications could be considered as an extended study or complement work of Iwanaga et al., who evaluated the most recent 50 articles mentioning MC and IAC (but not IDC) up to February 2020, respectively. The current results showed a dominance of the term $\mathrm{MC}$ in the academic literature regardless of time, journal category, and journal subspecialty within dentistry. Geographic location, however, seemed to affect the choice of terms, as Saudi Arabia, and to a lesser extent, Iran, showed a heightened ratio of IAC compared to other countries. These findings were consistent to Iwanaga et al., who also reported that these two Middle East countries largely preferred IAC than MC when the most recent articles were considered. Meanwhile, the current findings also revealed that IDC seemed to be more favored by UK than other countries. 
Agreeable to Iwanaga et al., the anatomy journals showed the highest ratio of publications that exclusively used the term MC. However, the balanced use between $\mathrm{MC}$ and IAC in dentistry journals, as well as the preference towards the exclusive use of IAC in journals outside the fields of anatomy and dentistry, were not observed in the current analysis. When the entire literature across time was considered, the most recurring journal categories such as dentistry, radiology, surgery, and medicine all showed a preference towards the use of MC. The differences could be due to different sampling: Iwanaga et al. analyzed the 50 most recently published MC and IAC papers indexed by PubMed, whereas the current study analyzed the entire literature indexed by WoS.

It is true that word choice matters in many scenarios, but the influence may not be clear-cut. For example, in social science, it was found that Europeans perceived "global warming" and "climate change" as equally serious issues, whereas the Americans weighed one over the other as a more serious issue depending on their political background (Villar \& Krosnick, 2011). Similarly, it was found that the participants of psychology experiments did not particularly feel coerced into an informed consent no matter if the consent form was written in first, second, or third person perspective (Edlund et al., 2014). Meanwhile, word choice is also an important issue in clinical settings. For instance, in intensive care unit, it was advised to avoid saying withholding or withdrawing "care" but rather "life-sustaining measure", because healthcare providers should never be careless, literally (Curtis et al., 2014). To the best of the author's knowledge, no prior study has investigated the effect of word choice in academic writing, such as academic impact in terms of averaged citations received. In the current study, word choice seemed to have no significant influence over the median citation count.

\section{CONCLUSION}

Based on the analysis of the overall literature, it was reaffirmed that $\mathrm{MC}$ remained the most preferred term compared to IAC and IDC in most scenarios. Among the five most recurring journal category, $\mathrm{MC}$ was embraced the most by anatomy but the least by medicine. Dentistry was in the middle, but even within dentistry the preference of MC differed: it was more embraced by dental radiology than dental surgery. Different from the findings by (Iwanaga et al.), this study did not find an increasing preference of IAC over MC, but geographic location seemed to matter, as some countries showed a higher preference for IAC than the others. The argumentation of renaming $\mathrm{MC}$ as IAC has yet to accumulate considerable traction in the academic literature. Of course standardized terminology would eliminate confusion (Yeung, 2017) and simplify literature search (Yeung et al., 2018, 2020), but it would not be practical in this scenario.

Limitations. It was reasoned that many publications dealt with the inferior alveolar nerve (also known as inferior dental nerve), which is highly relevant to lower third molar surgery in dentistry. It might be interesting to evaluate if publications dealing with this nerve tended to name MC as IAC. However, the inferior alveolar nerve is actually a branch of the mandibular nerve instead of its synonym. To compare the mentioning of MC, IAC, and IDC among publications dealing with mandibular nerve and inferior alveolar nerve respectively would be similar to comparing apples and oranges. Moreover, it was not possible to reveal the intention of the authors who used MC, IAC, and/or IDC concomitantly. It could be perceived as synonyms, or it could be done intentionally to improve the article visibility when fellows perform a literature search. Meanwhile, publications not indexed by WoS would be missed in this analysis.

ACKNOWLEDGEMENTS. Funding: This work was supported by departmental funding only.

YEUNG, A. W. K. El uso de los términos canal mandibular, canal alveolar inferior y canal dental inferior en la academia: un análisis bibliométrico. Int. J. Morphol., 39(4):1058-1062, 2021.

RESUMEN: Un estudio reciente encontró que el canal mandibular ha sido llamado en los últimos, canal alveolar inferior en ciertas categorías de revistas, países y departamentos con algunos autores asociadas a estas. El canal también se puede denominar canal dental inferior término que no se incluyó en ese estudio. Este análisis bibliométrico se realizó para evaluar la literatura relevante e investigar la frecuencia del uso de canal alveolar inferior en el tiempo. Se buscó en la base de datos electrónica de Web of Science Core Collection para identificar publicaciones que mencionan exclusivamente canal mandibular, canal alveolar inferior, canal dental inferior y publicaciones que las mencionan en combinaciones. El año de publicación, el país de los autores contribuyentes, la categoría de la revista, el título de la revista y el recuento de citas se registraron para las publicaciones resultantes. Se analizaron 1152 publicaciones. Desde la década de 1990, canal mandibular siempre ha sido el término predominante, mientras que canal alveolar inferior pareció volverse algo más popular en la década de 2010. Las revistas de odontología, cirugía, radiología, anatomía y medicina mostraron una preferencia por canal mandibular. Las principales revistas de cirugía dental tenían una proporción más alta de uso de canal alveolar inferior que sus con- 
trapartes de radiología dental. Los principales 20 países mostraron una preferencia por canal mandibular, excepto Arabia Saudita, que tenía un $57,7 \%$ de las publicaciones que usaban exclusivamente canal alveolar inferior. Las publicaciones que mencionan canal mandibular, canal alveolar inferior e canal dental inferior no difirieron en el recuento promedio de citas. El término canal mandibular todavía predomina en todos los campos académicos. El término canal alveolar inferior mostró un mayor uso en la década de 2010 sin una tendencia creciente, sin embargo el argumento de cambiar el nombre de canal mandibular a canal alveolar inferior en el futuro deberá ser ratificado.

PALABRAS CLAVE: Odontología; Anatomía; Canal mandibular; Canal alveolar inferior; Canal dental inferior.

\section{REFERENCES}

Curtis, J. R.; Sprung, C. L. \& Azoulay, E. The importance of word choice in the care of critically ill patients and their families. Intensive Care Med., 40(4):606-8, 2014.

Edlund, J. E.; Hartnett, J. L.; Heider, J. D.; Perez, E. J. \& Lusk, J. Experimenter characteristics and word choice: best practices when administering an informed consent. Ethics Behav., 24(5):397-407, 2014.

Iwanaga, J.; Matsushita, Y.; Decater, T.; Ibaragi, S. \& Tubbs, R. S. Mandibular canal vs. inferior alveolar canal: Evidence-based terminology analysis. Clin. Anat., 34(2):209-17, 2021.

Mortazavi, H.; Baharvand, M.; Safi, Y. \& Behnaz, M. Common conditions associated with displacement of the inferior alveolar nerve canal: A radiographic diagnostic aid. Imaging Sci. Dent., 49(2):79-86, 2019.

Mortazavi, H.; Baharvand, M.; Safi, Y.; Dalaie, K.; Behnaz, M. \& Safari, F. Common conditions associated with mandibular canal widening: A literature review. Imaging Sci. Dent., 49(2):87-95, 2019.

Villar, A., \& Krosnick, J. A. Global warming vs. climate change, taxes vs. prices: Does word choice matter? Clim. Change, 105:1-12, 2011.

Yeung, A. W. K. Tube shift or tube tilt? The terminology of dental radiography is heterogeneous relative to radiological convention. Hong Kong Med. J., 23(1):97-8, 2017.

Yeung, A. W. K.; Heinrich, M. \& Atanasov, A. G. Ethnopharmacology-A bibliometric analysis of a field of research meandering between medicine and food science? Front. Pharmacol., 9:215, 2018.

Yeung, A. W. K.; Heinrich, M.; Kijjoa, A.; Tzvetkov, N. T. \& Atanasov, A. G. The ethnopharmacological literature: An analysis of the scientific landscape. J. Ethnopharmacol., 250:112414, 2020.
Corresponding author:

Dr. Andy Wai Kan Yeung

Oral and Maxillofacial Radiology

Applied Oral Sciences and Community Dental Care

Faculty of Dentistry

University of Hong Kong

Hong Kong

CHINA

E-mail: ndyeung@hku.hk

Received: 13-04-2021

Accepted: 13-05-2021 